\title{
Holmium YAG Laser Ureterolithotripsy versus Extracorporeal Shock Wave Lithotripsy in Management of Proximal Ureteric Stones; Prospective Randomized Study Hussein Hosny Mahmoud Farag, Mohammed AbdallahHendawy, Mohammed Shukry Hussein \\ Department of Urology; Faculty of Medicine; Al-Azhar University; Cairo \\ Corresponding author: Mohammed Shukry Hussein, Mobile: 01019594319; Email: dr_gladiator2020@yahoo.com
}

\begin{abstract}
Background: Shockwave Lithotripsy (SWL) and ureteroscopy using Holmium Laser are effective and minimally invasive procedures for treating proximal ureteric stones $\leq 1.5 \mathrm{~cm}$. However, there is still a debate of which one is more suitable for the proximal ureteric stones. Different studies have reported a variety of outcomes of SWL and ureteroscopy, as the both treatments use advanced instruments, they offer few complications and good outcomes among urologists.

Objective: To evaluate the safety and efficacy of ureteroscopy using Holmium YAG LASER for proximal ureteric stone $\leq 1.5 \mathrm{~cm}$ compared to SWL. Patients and Methods: It was a randomized prospective trial comparing ureteroscopy with HO: YAG Laser to (SWL) in managing proximal ureteric stones, done in the period from April 2018 to April 2019. It included 40 patients with upper ureteral stones and were randomly divided into two groups:

Group A: 20 patients treated by ESWL. Group B: 20 patients treated by ureteroscopy using LASER lithotripsy.

Results: There was no significant difference between the two groups regarding patients and stones criteria as maximal diameter, $\mathrm{HU}$ and position opposite vertebrae, degree of hydronephrosis and overall success rate.

Conclusion: ESWL and Ho-YAG laser lithotripsy are comparable in managing proximal ureteric stones in term of safety and efficacy. URS has the advantage of higher SFR from the first session and prolonged radiation exposure time. ESWL has the advantage of no need of anesthesia and no hospital stay as it was done as outpatient and this should be considered when counseling the patient with proximal ureteric stone.
\end{abstract}

\section{INTRODUCTION}

Urolithiasis is considered a health problem of international importance. Egypt falls into AfroAsian stone belt stretching from Egypt, Iran, India, Thailand to Republic of Indonesia. A multiple treatment options are available for proximal ureteric calculi. Revolutionary advances within the minimally invasive and noninvasive management of urolithiasis over the past 20 years have greatly increased the possibility of stone removal ${ }^{(1)}$.

Concerning proximal ureteric calculi, both extracorporeal shock wave lithotripsy (ESWL) and ureteroscopy (URS) are effective treatment modalities and each has its own benefits and drawbacks ${ }^{(2)}$.

ESWL is a noninvasive technique for the treatment of stone disease. It is widely employed in clinical treatment and this method of removing stones has benefits like easy operation, less pain and lower price (3). Although ESWL is one of the most commonly used strategies in the treatment of ureteric stones, it was observed that some elements of gravel couldn't be ejected spontaneously after treatment, and this sets limits for the use of SWL $^{(4)}$.

Open surgery is being replaced by URSL, that uses the holmium laser technology. It can crush variable stones with no matter composition and density with little ureteric mucosal harm ${ }^{(5)}$. The URSL has the advantage of being adequate and immediate in decompression of the obstruction in a single session with considerably higher stone-free rates however it has the disadvantage of having a higher complication rates than ESWL (9-11\% vs 4\%) ${ }^{(6)}$. ESWL and ureteroscopy are effective and minimally invasive procedures however there is still as debate of which one is more appropriate for proximal ureteric stones. Different studies have reported a variety of outcomes of ESWL and ureteroscopy, as each treatment uses advanced instruments, they have few complications and good outcomes among urologists ${ }^{(7)}$.

\section{AIM OF THE WORK}

The aim of our work was to evaluate safety and efficacy of ureteroscopy using Holmium YAG LASER for proximal ureteric stone $\leq 1.5 \mathrm{~cm}$ compared to (SWL).

\section{PATIENTS AND METHODS}

Study design: It was a randomized interventional prospective clinical trial comparing ureteroscopy with Holmium YAG Laser to SWL in managing proximal ureteric stones.

Time frame: The study was conducted for 1 year starting from April 2018 to April 2019 in the Department of Urology at Al-Hussein and SayedGalal University Hospitals, Cairo.

Aim of the study: Evaluation of safety and efficacy of ureteroscopy with Holmium YAG Laser for proximal ureteric stone $\leq 1.5 \mathrm{~cm}$ compared to SWL.

Inclusion criteria: Both genders with symptomatic single proximal ureteric stone $\leq 1.5 \mathrm{cmin}$ maximum dimension.

Exclusion criteria: Pediatric patients less than 18 years old. Pregnant females. Urinary tract obstruction distal to the stone. Radiolucent stones. Patients with severe orthopedic deformities. Patients with uncorrectable bleeding disorders. Past history of lower ureterolithomy or reimplanted ureter.Patients with congenital renal anomalies (ectopic, horseshoe and duplex), calyceal 
diverticulum, pelvi-ureteric junction obstruction and ureteric strictures. Patients with multiple ureteric stones. Morbid obese patients.Untreated urinary tract infection.

Method: Initially 40 patients were enrolled in the study and were randomly divided using closed envelope method into two groups: Group A: 20 patients treated by ESWL. Group B: 20 patients treated by ureteroscopy using LASER lithotripsy.

Ethical considerations: The study was approved by the Ethics Committee at Al-Azhar Faculty of Medicine, Cairo. The procedure was explained to the patients and each patient provided informed consent before inclusion in the study.

\section{Preoperatively in both groups: \\ Clinical assessment: All Patients were} subjected to full history taking including symptoms, medical and surgical history, drug allergy and current medication. Examination was done generally and locally to look for associated conditions or causes for urolithiasis.

Radiological assessment: KUB: It was done for detection of the density and level of the stone in comparison to the lumber vertebrae.

Abdomino-pelvic U/S: It was done for all patients as preliminary examination to detect any stones, the degree of hydronephrosis or any other pathological findings in kidneys as renal masses, polycystic kidney, infected renal cyst.

Computed tomography urinary tract (CTUT): it was also done with estimation of Hounsfield unit (HU) that was done for all patients preoperatively to look for the number, site and size of the calculi, degree of hydronephrosis (HUN) as well as anomalies and associated conditions.

The average CTUT attenuation value as the representative HU was measured by drawing a region of interest smaller than the stone in the image showing the stone in the largest dimension.Hydronephrosis classified according to the dilatation of the pelvicalyceal system and thinning of cortex on CTUT ${ }^{(8)}$.

Table (1): Hydronephrosis - grading of dilatation of hydronephrosis

\begin{tabular}{|c|c|}
\hline Grade & Description \\
\hline Grade I (mild) & $\begin{array}{c}\text { Dilatation of renal pelvis without } \\
\text { dilatation of the calices. } \\
\text { Dilatation of renal pelvis and } \\
\text { calices that become convex; no } \\
\text { signs of cortical thinning. }\end{array}$ \\
\hline $\begin{array}{c}\text { Grade III } \\
\text { (moderate) }\end{array}$ & Presence of cortical thinning. \\
\hline $\begin{array}{c}\text { Grade IV } \\
\text { (marked) }\end{array}$ & $\begin{array}{c}\text { Massive dilatation of renal pelvis } \\
\text { and calices, sever cortical thinning. }\end{array}$ \\
\hline
\end{tabular}

\section{Laboratory assessment:}

All patients underwent the following laboratory tests: Complete Blood Picture (CBC) to assess hemoglobin level, total leucocytic count and platelet levels. Bleeding profile (PT, PTT and INR) to exclude coagulopathy. Serum chemistry Alanine aminotransferase (ALT), Aspartate aminotransferase (AST) to assess liver function. Serum Creatinine, urea and uric acid to assess renal function and renal perfusion. Body Mass Index (BMI) was calculated by dividing the weight $(\mathrm{kg})$ by square of the height in meters.

ESWL Group: ESWL was performed using the third-generation Dornier lithotripter S II (Dornier, Germany) (Fig. 1) that deploys electromagnetic shock waves for fragmentation. On the day of the procedure no food intake was allowed for 8 hours prior to SWL. Vital signs (blood pressure, temperature, and pulse) were assessed. If the BP was $140 / 90$ or more, or temperature over 37.5 , pulse over $100 / \mathrm{min}$, the ESWL session would be postponed, internal medicine consultation and another session was arranged when the patient became vitally stable.

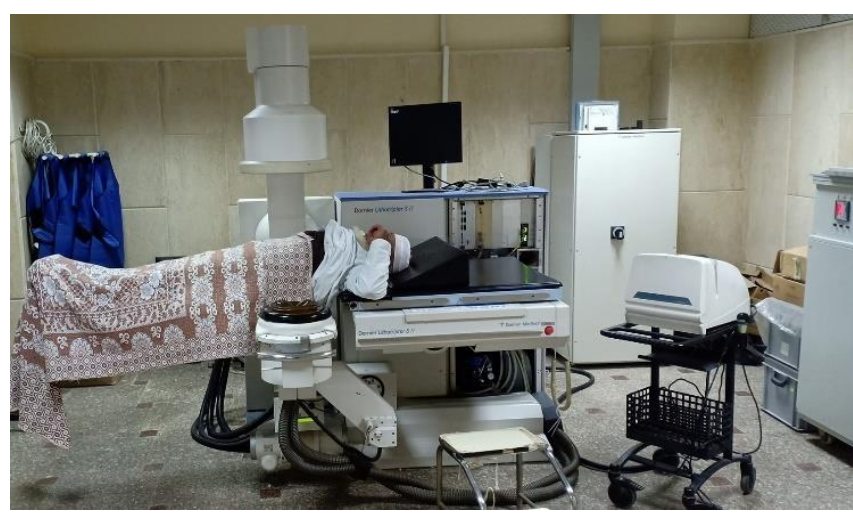

Figure (1): Patient supine position during lithotripsy by Dornier Lithotriptor SII.

Operative technique: All patients received intravenous analgesia in the form of $5 \mathrm{mg}$ nalbuphine HCL (Nalufin ${ }^{\circledR}$ ) and/or tenoxicam (Epicotel $\left.{ }^{\circledR}\right)$ vial/iv. Intravenous fluid administration was given to all patients throughout the procedure and all patients were treated in supine position with water cushion adjusted below the flank. Fluoroscopy was used for stone localization and fluoroscopy time was increased with the increase in stone burden. Every treatment session started at energy level of $10 \mathrm{KV}$. This low energy level was to minimize the "startle" response from the patient when the first shocks are administered thus preventing the movement of the stone away from the focus of SWs. Then, the power gradually increased by $10 \mathrm{kv}$ every 100 shocks until the desired energy level is obtained $(90 \mathrm{kv})$ according to the stone fragility and patient tolerance. The maximum intensity level was $(90 \mathrm{kv})$. SWs were given at rate of 70-80/minute for all patients. We confirmed the positioning of the stone and monitored the progress of fragmentation by fluoroscopy and snap shot imaging at intervals of 300-500 shocks. The procedure was ended when satisfactory fragmentation (when fragments became $\leq 4 \mathrm{~mm}$ ) was seen on fluoroscopy or after 3500 shock waves had been delivered. All treatment parameters which include operative time, number and energy of SWs per session, number of sessions were recorded. At the end of each 
session and on discharge, patients were instructed to drink liberal fluids. Oral analgesia (diclofenac potassium OD), alpha blocker (tamsulosin0.4 capsule/24hs for a week) and antibiotic (ciprofloxacin/12hs for 5days) was also prescribed to be taken if needed. They were also instructed to document passage of fragments and re-check if they developed hematuria with clots, fever and sever colic.

Follow up: All patients were reviewed two weeks after the first session to assess if there is any hematuria, passage of fragments, fever, and colic. All patients were investigated two weeks after the first session by plain (K.U.B) to assess disintegration of stones and the need for further sessions, if the KUB was free, ultrasound was done to ensure patent system. Disintegration and clearance were noted and a decision was given regarding the need for further session if fragments were $4 \mathrm{~mm}$ or greater. Successful treatment was considered if the KUB revealed stone free or presence of fragments $\leq 4 \mathrm{~mm}$ (primary end point). For patients who needed more than one session, the duration between each session was 2 weeks to give chance for tiny fragments to pass. If another session was done, it was added to the patient's own file with separate entries for the same items as in 1st session. Three sessions of SWL with no evidence of disintegration or fragmentation was considered as unsuccessful result and another treatment modality was chosen for the patient (failure of treatment). Three months after the last session, a pelvi-abdominal ultrasound was done to assess patency of the pelvicalyceal system and to detect any element of hydronephrosis.

\section{Ureteroscopy group:}

Preoperative preparation: Ultrasonography, KUB and CTUT was done as mentioned above. All patients with sterile urine were given prophylactic antibiotic in the form of $1 \mathrm{gm}$ ceftriaxone ${ }^{\circledR} \mathrm{I}$.V. within one hour before the procedure. Patients with infected urine were given organism-specific antibiotic according to culture and sensitivity tests at least 72 hours before the procedure.

Anesthesia: Spinal anesthesia was preferred but general anesthesia in some cases as spinal deformity or anxious patients.

Patients positioning: Patients were placed in the dorsal lithotomy position with the leg of the ipsilateral side of the stone mildly extended and abducted to reduce the pelvic curvature of the ureter to allow easy access to the upper ureter with the semirigid URS (figure12). Fluoroscopy was positioned with apron protection for the surgeon, nurse and anesthetic doctor.

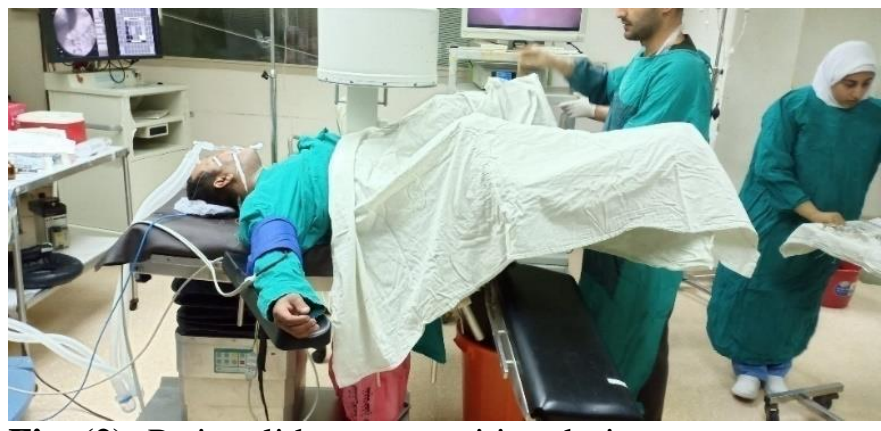

Fig. (2): Patient lithotomy position during ureteroscopy

Operative technique: Cystoscopy done using the $22 \mathrm{~F}$ sheath to inspect the bladder and orifices and pass a guide wire to the renal collecting system and to dilate the ureteric orifice. Retrograde study was done to localize the stone and show the course of the ureter. A guide wire was passed beyond the stone into the renal collecting system under fluoroscopy guidance. Ureteric dilatation was not performed routinely, but only when the ureteroscope could not be advanced to the ureteric orifice directly or using the guide wire. It was done using balloon dilator.

Advancement of the semirigidureteroscope (karlStorz, Germany 7.5Fr.) over/along the guidewire negotiating the curves of the urethra, finding the way from the bladder neck, across the bladder and into the ureteric orifice. Visual identification of the stone under fluid irrigation by normal saline.

Stone fragmentation was done using a $30 \mathrm{~W}$ holmium: YAG laser (Auriga QI). (fig13). A 200- 365 $\mu \mathrm{m}$ laser fiber with an energy output of 1.2-8 $\mathrm{J}$ at $8-12$ $\mathrm{Hz}$ was used but the joule and hertz of energy could be changed during the operation according to the stone hardness and efficacy of lithotripsy. The fragmentation procedure was continued until all stone fragments were $\leq 4 \mathrm{~mm}$.

Stone fragments were dealt according to their site and size; small fragments were extracted by forceps and larger fragments in the lower ureter were dealt with by dusting technique. After finishing the procedure, retrograde study was done in some cases to show if there was a residual proximally migrated stone or extravasation. A JJ stent was applied if residual fragments were left or migrated stone. Ureteric catheter was inserted in 5 cases after the procedure for 24 hours to relieve post-operative pain and avoid obstruction caused by edema. A cystourethral catheter was inserted in all cases for $24 \mathrm{hs}$.

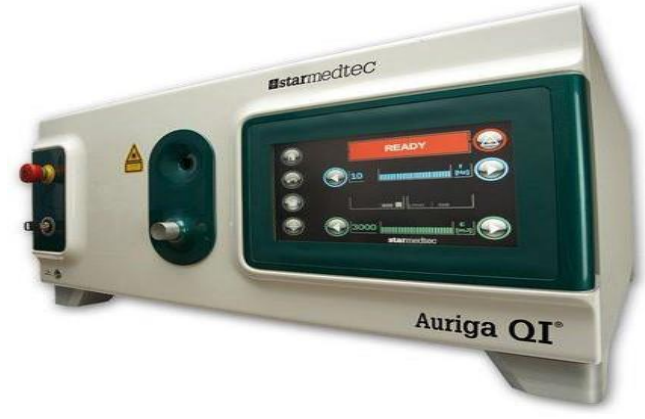

Fig. (3): Auriga QI 30 watt. 
Operative time was defined as the time of starting anesthesia till the end of the procedure.

Postoperative: All patients were admitted in the floor for 24 hours and were followed up after the procedure to assess presence of renal colic, signs of urosepsis (fever and rigor) and color of urine. All patients underwent a KUB 24 hours postoperative. Patients were given prophylactic intravenous antibiotic as given with induction of anesthesia, plenty of intravenous fluids and regular analgesic (paracetamol IV/8hs) then discharged on oral antibiotic (ciprofloxacin $500 \mathrm{mg}$ tab/12hs for 10 days), Alpha blocker (Tamsulosin $0.4 \mathrm{mg} / 24$ hours for a week) was given in some cases to allow passage of small residual fragments and antimuscarinic (Solifenacin 5mg tab/24hs) to relieve voiding symptoms related to the stent.

Ultrasonography and KUB was done for all patients within 3 months postoperatively to follow up the success rate and complications.

Successful treatment was considered if the KUB revealed stone free or presence of fragments $\leq 4 \mathrm{~mm}$ (primary end point)

Patients who were found to have no residual stones or small fragments $\leq 4 \mathrm{~mm}$ were scheduled for double-J removal if applied.

If there was large residual stone $>4 \mathrm{~mm}$, a later date for another URS or ESWL was arranged (failure of treatment).

\section{RESULTS}

Table (2): Age distribution in SWL and URS groups:

\begin{tabular}{|l|c|c|c|c|c|}
\hline \multicolumn{1}{|c|}{$\underline{\text { AGE }}$} & Mean \pm SD & (Range) & Median & t-test & p-value \\
\cline { 1 - 3 } LASER group & $39.4 \pm 8.8$ & $(25-53)$ & 37 & 0.9 & 0.3 \\
\cline { 1 - 3 } ESWL group & $42.2 \pm 9.9$ & $(27-59)$ & 44 & & \\
\hline
\end{tabular}

In this table, there was no significant difference between the two groups as P-value is $>0.05$.

Table (3): Distribution of the studied groups as regards sex.

\begin{tabular}{|c|c|c|c|c|c|c|}
\hline \multirow{2}{*}{ SEX } & \multicolumn{2}{|c|}{ ESWL } & \multicolumn{2}{|c|}{ URS } & \multirow{2}{*}{$\mathbf{X}^{2}$} & \multirow{2}{*}{ P. value } \\
\cline { 2 - 5 } & $\mathrm{N}$ & $\%$ & $\mathrm{~N}$ & $\%$ & & \\
\hline MALE & 15 & $79 \%$ & 15 & $79 \%$ & \multirow{2}{*}{ FET } & 1 \\
\hline FEMALE & 4 & $21 \%$ & 4 & $21 \%$ & & \\
\hline
\end{tabular}

FET $=$ Fischer Exact test.

In this table, there was no significant difference between the two groups as $\mathrm{P}$ value is $>0.05$ (both groups were matched).

Table (4): Comparing SWL and URS groups pre-operative data evaluation

\begin{tabular}{|c|c|c|c|c|c|c|c|}
\hline \multirow[b]{2}{*}{ Past History } & & \multicolumn{2}{|c|}{ LASER group } & \multicolumn{2}{|c|}{ ESWL group } & \multirow[b]{2}{*}{$\chi^{2}$} & \multirow[b]{2}{*}{ p-value } \\
\hline & & $\mathbf{N}(\mathbf{1 9})$ & $\%$ & $\mathbf{N}(19)$ & $\%$ & & \\
\hline \multirow[t]{2}{*}{ D.M } & No & 19 & $100.0 \%$ & 17 & $89.5 \%$ & \multirow{2}{*}{ FET } & \multirow[b]{2}{*}{0.4} \\
\hline & Yes & 0.0 & $0.00 \%$ & 2 & $10.5 \%$ & & \\
\hline \multirow[t]{2}{*}{ Hypertension } & No & 17 & $89.5 \%$ & 17 & $89.5 \%$ & \multirow{2}{*}{ FET } & \multirow[b]{2}{*}{1} \\
\hline & Yes & 2 & $10.5 \%$ & 2 & $10.5 \%$ & & \\
\hline
\end{tabular}

In this table, there was no significant difference between the two groups regarding the past history as P. value is $>0.05$.

Table (5): comparing BMI between ESWL and URS groups

\begin{tabular}{|c|c|c|c|c|}
\hline $\begin{array}{c}\text { Body Mass Index } \\
(\text { BMI) }\end{array}$ & ESWL & URS & T-test & P-Value \\
\hline Mean \pm SD & $29.5 \pm 3.7$ & $28.7 \pm 3.9$ & 0.648 & 0.520 \\
\hline
\end{tabular}

In this table, there was no significant difference between the two groups regarding the BMI as Pvalue is $>0.05$.

Table (6): Comparing creatinine and hemoglobin levels between URS and ESWL groups

\begin{tabular}{|c|c|c|c|c|}
\hline \multirow{3}{*}{ Variable } & URS group & ESWL group & \multirow{2}{*}{ t-test } & \multirow{2}{*}{ P-value } \\
\cline { 2 - 4 } & $\begin{array}{c}\text { Mean } \pm \text { SD (Range) } \\
\text { Median }\end{array}$ & $\begin{array}{c}\text { Mean } \pm \text { SD (Range) } \\
\text { Median }\end{array}$ & & 0.1 \\
\hline Creatinine & $1.17 \pm 0.3$ & $\begin{array}{c}1.12 \pm 0.2 \\
1.1\end{array}$ & 0.9 & 0.1 \\
\hline Hb & 1 & $\begin{array}{c}13.8 \pm 1.3 \\
14.1\end{array}$ & 0.5 & 0.5 \\
\hline
\end{tabular}

In this table, there was no significant difference between the two groups regarding creatinine and hemoglobin levels as Pvalue is $>0.05$. 
Table (7): Criteria of the ureteric Stones

\begin{tabular}{|c|c|c|c|c|c|c|c|}
\hline \multirow{2}{*}{\multicolumn{2}{|c|}{ Variable }} & \multicolumn{2}{|c|}{ ESWL } & \multicolumn{2}{|c|}{ LASER } & \multirow{4}{*}{$\begin{array}{l}\mathbf{X}^{2} \\
0.9\end{array}$} & \multirow{4}{*}{$\begin{array}{c}\begin{array}{c}\text { P- } \\
\text { Value }\end{array} \\
0.3\end{array}$} \\
\hline & & \multirow{2}{*}{$\frac{N(19)}{10}$} & \multirow{2}{*}{$\begin{array}{c}\% \\
52.6\end{array}$} & \multirow{2}{*}{$\frac{N(19)}{13}$} & \multirow{2}{*}{$\begin{array}{c}\% \\
68.4\end{array}$} & & \\
\hline Stone side & Right ureter & & & & & & \\
\hline Stone side & Left ureter & 9 & 47.4 & 6 & 31.6 & & \\
\hline \multirow{2}{*}{ Stone site } & Upper ureter & 18 & 94.7 & 15 & 78.9 & \multirow{2}{*}{0.2} & \multirow{2}{*}{0.9} \\
\hline & Middle ureter & 1 & 5.3 & 4 & 21.1 & & \\
\hline & & \multicolumn{2}{|c|}{ ESWL } & \multicolumn{2}{|c|}{ LASER } & T-Test & $\begin{array}{c}\text { P- } \\
\text { Value }\end{array}$ \\
\hline & & Mean \pm SD & $\begin{array}{c}\text { Median } \\
\text { (range) }\end{array}$ & Mean \pm SD & $\begin{array}{l}\text { Median } \\
\text { (range) }\end{array}$ & & \\
\hline \multirow{2}{*}{\multicolumn{2}{|c|}{ Density (HU) }} & $1111.5 \pm$ & 1115 & $1009.8 \pm 289.4$ & 1122 & \multirow{2}{*}{1.4} & \\
\hline & & 251.6 & $(720-1600)$ & & $(516-1489)$ & & 0.2 \\
\hline \multirow{2}{*}{\multicolumn{2}{|c|}{ Stone size $(\mathbf{m m})$}} & \multirow{2}{*}{$11.2 \pm 2.4$} & 11 & $11.6 \pm 1.7$ & 11 & \multirow{2}{*}{0.8} & \multirow{2}{*}{0.3} \\
\hline & & & $(7-15)$ & & $(7-15)$ & & \\
\hline \multicolumn{2}{|c|}{ Stone Size } & No. (19) & $\%$ & No. (19) & $\%$ & $\mathbf{X}^{2}$ & $\begin{array}{c}\text { P- } \\
\text { Value }\end{array}$ \\
\hline \multicolumn{2}{|c|}{$\leq \mathbf{1 0}(\mathrm{mm})$} & 8 & $42.10 \%$ & 9 & $47.40 \%$ & \multirow{2}{*}{0.4} & \multirow{2}{*}{0.5} \\
\hline \multicolumn{2}{|c|}{ More than 10 but $\leq 15 \mathrm{~mm}$} & 11 & $57.90 \%$ & 10 & $52.60 \%$ & & \\
\hline
\end{tabular}

In this table, there was no significant difference between the two groups regarding the stone criteria as Pvalue is $>0.05$.

Table (8): Comparing the procedural time between LASER and ESWL groups

\begin{tabular}{|c|c|c|c|c|c|}
\hline \multirow{2}{*}{ Variable } & \multicolumn{1}{|c|}{ ESWL } & URS & \multirow{2}{*}{ t-test } & P-Value \\
\cline { 2 - 5 } & Mean \pm SD & Mean \pm SD & 4.82 & $<\mathbf{0 . 0 5}(\mathbf{S})$ \\
\hline Operative time (min) & & & 9.07 & $\begin{array}{c}<\mathbf{0 . 0 5} \\
(\mathbf{S})\end{array}$ \\
\hline $\begin{array}{c}\text { Overall procedural } \\
\text { time(min) }\end{array}$ & $143.78 \pm 27.21$ & $79.05 \pm 15.06$ & 12.5 & $\begin{array}{c}<\mathbf{0 . 0 5} \\
(\mathbf{S})\end{array}$ \\
\hline $\begin{array}{c}\text { Radiation exposure } \\
\text { time (sec) }\end{array}$ & $159.78 \pm 17.28$ & $48.57 \pm 6.3$ & 24.6 & $<\mathbf{0 . 0 5}$ \\
\hline $\begin{array}{c}\text { Overall radiation } \\
\text { exposure time (min) }\end{array}$ & $7.7 \pm 1.63$ & $0.8 \pm 0.1$ & & \multicolumn{2}{|c|}{} \\
\hline
\end{tabular}

In this table, regarding the oper tive time of ESWL and URS groups, there was a sighfficant difference between both modalities in favor of ESWL as the Pvalue was less than 0.05 but when considering the overall procedural time there was a significant difference between both modalities in favor of URS.ATso, here was a significicant difference in favor of URS regarding the radiation exposure time in seconds and the overall radiation exposure time in minutes.

Table (9): Comparing complications błtween LASER and ESWL groups.

\begin{tabular}{|c|cc|cc|c|c|}
\hline Complications & \multicolumn{2}{|c|}{$\begin{array}{c}\text { LASER group N (19) } \\
\mathbf{\%}\end{array}$} & \multicolumn{2}{|c|}{$\begin{array}{c}\text { ESWL group } \\
\mathbf{N}(\mathbf{1 9 )} \boldsymbol{\%}\end{array}$} & P-value \\
\hline Voiding symptoms & 5 & $26.3 \%$ & 2 & 10.5 & 2.7 & $\mathbf{0 . 0 3 * ( S )}$ \\
\hline Gross hematuria & 2 & $10.5 \%$ & 4 & $21 \%$ & 1.8 & 0.6 \\
\hline Renal colic & 2 & $10.5 \%$ & 5 & $26.3 \%$ & 2.7 & $\mathbf{0 . 0 3 * ( S )}$ \\
\hline Stone migration & 1 & $5.3 \%$ & 0 & $0.00 \%$ & 1.2 & 0.9 \\
\hline Stein Strasse & 0 & $0.00 \%$ & 2 & $11.1 \%$ & 2.6 & $\mathbf{0 . 0 4}$ \\
\hline Fever & 1 & $5.3 \%$ & 0 & $0.00 \%$ & 1.2 & 0.9 \\
\hline $\begin{array}{c}\text { Ureteric injury and } \\
\text { Extravasation }\end{array}$ & 1 & $5.3 \%$ & 0 & 0 & 1.2 & 0.9 \\
\hline
\end{tabular}

Table (10): Comparing stone free rate between LASER and ESWL groups 


\begin{tabular}{|c|c|c|c|c|c|c|}
\hline \multirow[t]{2}{*}{ Stone free rate (SFR) } & \multicolumn{2}{|c|}{ LASER } & \multicolumn{2}{|c|}{ ESWL } & \multirow{2}{*}{$\chi^{2}$} & \multirow{2}{*}{ p-value } \\
\hline & $\mathbf{N}$ & $\%$ & NO. (19) & $\%$ & & \\
\hline Overall success & $17(19)$ & $89.5 \%$ & 16 & $84.2 \%$ & \multirow{2}{*}{ FET } & \multirow{2}{*}{0.9} \\
\hline Failure rate & $2(19)$ & $10.5 \%$ & 3 & $15.8 \%$ & & \\
\hline $\begin{array}{c}\text { SFR in } \\
\text { Stones } \leq 10 \mathrm{~mm}\end{array}$ & $8(9)$ & $89 \%$ & $8(8)$ & $100 \%$ & FET & 1 \\
\hline $\begin{array}{c}\text { SFR in Stones }>10 \\
\mathrm{~mm}, \leq 15 \mathrm{~mm}\end{array}$ & $9(10)$ & $90 \%$ & $8(11)$ & $72.7 \%$ & FET & 0.586 \\
\hline
\end{tabular}

In this table, there was no significant difference between the two groups regarding the overall success rate, failure rate, SFR in stones $\leq 10 \mathrm{~mm}$ and SFR in stones $>10 \mathrm{~mm}$ and $\leq 15 \mathrm{~mm}$.

Table (11): Multivariate analysis for the relation between stone size and stone free rate in LASER and ESWL groups

\begin{tabular}{|c|c|c|c|c|c|c|}
\hline \multirow[t]{2}{*}{ Stone free rate (SFR) } & \multicolumn{2}{|c|}{ LASER } & \multicolumn{2}{|c|}{ ESWL } & \multirow{2}{*}{$\chi^{2}$} & \multirow{2}{*}{ p-value } \\
\hline & N. (19) & $\%$ & NO. (19) & $\%$ & & \\
\hline SFR in Stones $\leq 10 \mathrm{~mm}$ & $8(9)$ & $89 \%$ & $8(8)$ & $100 \%$ & \multirow[b]{2}{*}{0.4} & \multirow{2}{*}{$\begin{array}{c}0.5 \\
\text { (NS) }\end{array}$} \\
\hline $\begin{array}{c}\text { SFR in Stones }>10 \mathrm{~mm}, \\
\leq 15 \mathrm{~mm}\end{array}$ & $9(10)$ & $90 \%$ & $8(11)$ & $72.7 \%$ & & \\
\hline
\end{tabular}

In this table there was no statistically significant difference between the two groups regarding the Multivariate analysis for the relation between stone size and SFR as P-value is $0.5(>0.05)$.

Table (12): The SFR after one session of the both modalities

\begin{tabular}{|c|c|c|c|c|c|c|}
\hline & \multicolumn{2}{|c|}{ URS } & \multicolumn{2}{c|}{ ESWL } & \multirow{2}{*}{ T-test } & P-value \\
\hline $\begin{array}{c}\text { SFR after one } \\
\text { session }\end{array}$ & $\mathrm{N}$ & $\%$ & $\mathrm{~N}$ & $\%$ & \multirow{2}{*}{ FET } & $\begin{array}{c}<\mathbf{0 . 0 5} \\
(\mathbf{S})\end{array}$ \\
\cline { 2 - 5 }
\end{tabular}

This table showed a statistically significant difference between the URS and ESWL groups regarding the SFR after the 1st sessions of the both modalities in favor of URS as P-value is $(<0.05)$.

Table (13): Hospital stay in both groups

\begin{tabular}{|c|c|c|c|c|}
\hline \multirow{2}{*}{ Variable } & ESWL & URS & t-test & p-value \\
\hline & Mean \pm SD & Mean \pm SD & \multirow[t]{2}{*}{33.24} & \multirow{2}{*}{$<0.05(\mathrm{~S})$} \\
\hline Hospital stay (hours) & $2.47 \pm 0.45$ & $50.64 \pm 6.3$ & & \\
\hline
\end{tabular}

There was a significant difference between the two groups in favor of ESWL as P-value was $<0.05$.

Table (14): Relation between number of ESWL sessions and SFR

\begin{tabular}{|c|c|c|c|c|c|c|c|}
\hline \multirow{2}{*}{ Stone-free rate } & \multicolumn{2}{|c|}{ First session } & \multicolumn{2}{l|}{ Second session } & \multicolumn{2}{l|}{ Third session } & \multirow{2}{*}{ P-Value } \\
\cline { 2 - 7 } & $\mathbf{N}$ & $\mathbf{\%}$ & $\mathbf{N}$ & $\mathbf{\%}$ & $\mathbf{N}$ & $\mathbf{\%}$ & \\
\hline Success & 4 & 21 & 5 & 26.3 & 7 & 36.8 & $>0.05$ \\
\hline
\end{tabular}

In this table, there was a statistically insignificant difference in overall success rate with different session numbers as P-value was > 0.05. There were 3 failed cases in ESWL group that were converted to another modality of treatment (URS).

Table (15): The conversion rate in both groups.

\begin{tabular}{|c|c|c|}
\hline Conversion & $\mathbf{N}$ & $\%$ \\
\hline ESWL & 3 & $15.8 \%$ \\
\hline URS & 2 & $10.5 \%$ \\
\hline
\end{tabular}

Conversion: ESWL failure was managed by ureteroscopy and failure of ureteroscopy was managed by ESWL due to stricture or edema of the ureter.

\section{DISCUSSION}

Although SWL and URS remain the most common modalities for the treatment of proximal ureteric stones, there is still an ongoing debate among the academicians and medical practitioners regarding the best treatment modality ${ }^{(9)}$. The technique of SWL started in the1980s, has stone free rate of nearly $90 \%$ and has resulted in the decrease of open surgical procedures for ureteric stones ${ }^{(\mathbf{1 0})}$. With subsequent advances of ESWL machine, it erased the limitations and promoted the efficiencies. Ureteroscopy was first described in 1912, but its use was not widely accepted until the late 1970's, at which time it became a standardized procedure. Concomitant with laser lithotripsy, an impressive $95 \%$ or 
more of the patients treated with were stone free after a single procedure. Most of the studies between ESWL and ureteroscopy are not conclusive and sometimes ambiguous ${ }^{(11)}$.

In this study, we compared the efficacy of ureteroscopic management using HO-YAG laser lithotripsy versus shock wave lithotripsy for treating proximal medium sized ureteric stones 5-15 mm regarding surgical efficacy and peri-operative morbidity.

In our study there was insignificant difference between the two groups regarding the age. These results come near to Cuiet al. ${ }^{(11)}$ Stone occurrence is relatively uncommon before age of 20 years old but peaks in incidence in the fourth to sixth decades of life ${ }^{(12)}$.

Male to female distribution in our study was 15:4 and 3.75:1 for both laser and ESWL groupsrespectively. This comes near to Sofia and Walter ${ }^{(13)}$ who reported that nephrolithiasis is more common in men(12\%) than women (6\%), (2:1) and in developing countries the male-to-female ratio in Arabic countries was 2.5:1 in Iraq and 5:1 in Saudi Arabia. There were no significant differences between the two groups in all parameters regarding diabetes mellitus and hypertension.

In our study, the BMI was $29.5 \pm 3.7$ for ESWL group and $28.7 \pm 3.9$ for URS one with no significant difference.

According to BMI classification, both groups fall in overweight area (25-29.9). This comes near to the mean BMI of the normal Egyptian population according to World Health Organization (WHO), which published that the overall mean BMI in Egypt was $29.2\left(\mathrm{~kg} / \mathrm{m}^{2}\right), 27.6$ $\left(\mathrm{kg} / \mathrm{m}^{2}\right)$ in males and $30.7\left(\mathrm{~kg} / \mathrm{m}^{2}\right)$ in females. Obesity is a significant contributing factor to urolithiasis with the WHO estimating that 1.7 billion people are overweight and obese worldwide. An increased incidence of urolithiasis of greater than $75 \%$ is seen in overweight and obese patients compared to their normal counterparts ${ }^{(14)}$.

In our study, the affected ureter was $52.65 \%$ to $47.6 \% \mathrm{RT}$ to LT for ESWL group and $68.4 \%$ to $31.6 \% \mathrm{RT}$ to LT in URS group with no significant difference between the two groups. The position of the stones in the ureter was $94.7 \%$ to $5.3 \%$ upper to middle parts in ESWL group, while it was $78.9 \%$ to $21.1 \%$ upper to middle parts in URS group. There was no significant difference between the two groups.

In Cui et $\boldsymbol{a l} .{ }^{(11)}$ the affected ureter was $47.5 \%$ to $52.2 \%$ RT to LT for ESWL group and $42.2 \%$ to $57.5 \%$ RT to LT for URS group with no significant difference between the two groups. The position of the stones in the ureter was $70 \%$ to $30 \%$ upper to middle parts in ESWL group, while it was $77.5 \%$ to $22.5 \%$ upper to middle parts in URS group. These stone criteria come near to that of our study.

In our study, the stone maximum diameter ( $\mathrm{mm}$ ) was 11.2 \pm 2.4 in ESWL group while it was 11.6 \pm 1.7 in the URS one, slightly more than Cui et al. ${ }^{(11)}$, which was 9.8 \pm 3.5 for ESWL and $10.2 \pm 4.3$ for URS groups. Of the 19 cases in ESWL group, 8 cases $(42.1 \%)$ had stones $\leq 10$ mm versus 9 cases (49.4\%) in the URS group. 11 patients (57.9\%) had stones $>10 \mathrm{~mm}$ but $\leq 15 \mathrm{~mm}$ versus 10
(52.6\%) in the URS group with insignificant P-value regarding stone diameter in our study denotes good randomization.

In our study, the mean Hounsfield Unit (HU) was $1111.5 \pm 251.6$ of the ESWL group while it was $1009.8 \pm 289.4$ of the URS group with no statistically significant difference between the two groups. Slightly more than Lopes et $\boldsymbol{a l} .{ }^{(15)}$ whose mean Hounsfield unit was 893 for SWL group and 1,165 for URS group. HU measurement of urinary calculi on pretreatment noncontrast computerized tomography may predict the stonefree rate ${ }^{(16)}$. Operation time ( $\left.\mathrm{min}\right)$ in our study were $59.35 \pm 9.5$ and $79.05 \pm 15.06$ for ESWL and URS respectively. Cui et al. ${ }^{(11)}$, operation time (min) was $40.0 \pm 10.0$ for ESWL group and $42.5 \pm 11.3$ for URS group, higher than in our study because ESWL of 3500 shocks at rate of $70 \mathrm{~Hz}$ took at least 50 minutes beside time taken for localization and sedation but in Cui $\boldsymbol{e t}$ al. ${ }^{(11)}$ shocks number ranged from 3000-3500 at rate of $80 \mathrm{~Hz}$ that needed less time. Higher also for URS group because the procedural time in our study was measured from starting anesthesia but Cui et al. ${ }^{(11)}$ measured it from starting introducing the ureteroscope.

Overall procedural time of ESWL group is the sum of times of each ESWL session taken by each case while of URS one is the time of starting anesthesia till the end of the procedure. In our study, it was $143.78 \pm 27.21$ min and $79.05 \pm 15.06 \mathrm{~min}$ in ESWL and URS groups respectively. There was a significant difference between both modalities in favor of URS, which is similar to Cui et $\boldsymbol{a l} .^{(\mathbf{1 1})}$, who reported a significant difference also between the both modalities in favor of URS.

In our study, there was a significant difference in used anesthesia (sedation for ESWL and regional spinal or general anesthesia for URS), position of the patient (supine for ESWL and dorsal lithotomy for URS). Yencilek et $\boldsymbol{a l l}^{(\mathbf{1 7 )}}$ reported similar results where ESWL group patients were treated under intravenous sedation with nalufen analgesia in supine position while URS group patients were treated under spinal or general anesthesia in lithotomy position.

Radiation exposure time for ESWL group is the time of exposure to fluoroscopy radiations during stone localization, monitoring fragmentation progress and confirming the stone focusing at intervals of 300-500 shocks, but for the URS group, it's the time of exposure to fluoroscopy radiations during stone localization, guide wire insertion, retrograde study and stenting at the end of the procedure. It was $159.78 \pm 17.28$ with median 162 seconds and $48.57 \pm 6.3$ with median 47 seconds in ESWL and URS groups respectively. Pricopet al. ${ }^{(18)}$ reported radiation exposure times of 209 and 286 seconds in ESWL and URS groups respectively, which was more than that in our study as we used fluoroscopy in pulse mode but they used it in a continuous mode. The overall radiation exposure time for ESWL group is the sum of radiation exposure times of all ESWL sessions taken by each case. It was $7.7 \pm 1.63$ and $0.8 \pm 0.1$ (min) in ESWL and URS groups respectively. There was a statistically highly significant difference between the both modalities 
in overall radiation exposure time in favor of URS. According to Preston et al. ${ }^{(18)}$ exposure to ionizing radiation at the age of 30 years old increases the incidence of cancers of parenchymal organs till the age of 70 years old by $35 \%$ per Gy for men and by $58 \%$ per Gy for women.

In our study, for URS group, hospital stay(hours) was $48.2 \pm 10.8$ versus $2.47 \pm 0.45$ in ESWL group with highly significant difference between both modalities in favor of ESWL group. This comes near to Cui et al. ${ }^{(11)}$ who reported $48.0 \pm 8.5$ hours in URS group

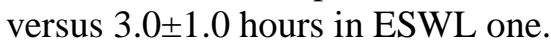

Regarding post-operative complications, we didn't find any severe complications during both procedures. We reported 4 out of 19 cases $(21 \%)$ of ESWL group opposite 2 cases (10.5\%) of URS group suffered from gross hematuria that managed conservatively with no need for intervention with no statistically significant difference between the both groups.

5 out of 19 cases (26.3\%) of ESWL group opposite 2 cases $(10.5 \%)$ of URS group suffered from renal colic requiring analgesia and medical expulsive therapy (MET) with a statistically significant difference in favor of URS. Macroscopic bleeding and renal colic for ESWL were caused by stone fragment movements and ureteric mucosa damage ${ }^{(\mathbf{1 9})}$. As most stone fragments were cleared during operation, fewer hematuria and renal colic were observed after ureteroscopy. Medical expulsion therapy was introduced following Ho:YAG laser lithotripsy as it accelerates the spontaneous passage of fragments and reduces episodes of colic (EAU guide lines). Most hematuria and renal colic disappeared after stone passage without special management.

There was a statistically significant difference between the both modalities in favor of ESWL regarding postoperative voiding symptoms. We reported 5 out of 19 cases $(26.3 \%)$ of URS group suffered from voiding symptoms in the form of urgency and dysuria opposite 2 cases of the ESWL group that suffered from the same symptoms due to passage of the fragments (medically treated). In our procedure of ureteroscopy each patient indwelled ureteric stent and moved out one month later, it might be the reason of these voiding symptoms of URS

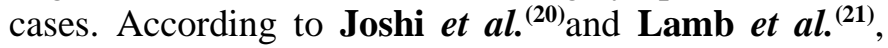
voiding symptoms and other discomforts after receiving a ureteral stent were unavoidable for ureteroscopy procedure. There is evidence that $\alpha$-blockers alleviate ureteral stent discomfort, but they don't work completely (22). There were no cases of URS group suffered from Stein Strasse opposite 2 out of 19 cases (11.1\%) of ESWL group with a statistically significant difference between both groups in favor of URS. These cases were eventually managed by conversion to URS with LASER lithotripsy.

In URS group, a single case (5.3\%) suffered from stone migration, another case (5.3\%) suffered from access failure with ureteric injury and extravasation and another one $(5.3 \%)$ suffered from post-operative fever, while in ESWL group there were no cases of stone migration or ureteric injury and extravasation or post-operative fever with no statistically significant difference between the both groups.

Cui et $\boldsymbol{a l} .{ }^{(11)}$ reported post-operative complications as follows: gross hematuria $20 \%$ of ESWL group while it was $2.5 \%$ of URS group. Renal colic occurred in $11.25 \%$ in ESWL group while it was $2.5 \%$ in URS one. Voiding symptoms occurred in $6.25 \%$ of ESWL group while it was $33.75 \%$ of URS group. No cases of Stein Strasse, stone migration or postoperative fever were reported. Also, Yencilek et $\mathbf{a l} .{ }^{(17)}$ reported postoperative complications as follows: hematuria $15.7 \%$ for ESWL group while $3.7 \%$ for URS one. Stone migration didn't occur in ESWL group but occurred in $16.7 \%$ of URS one. Stein Strasse occurred in $2.4 \%$ of ESWL group but didn`t occur in URS one. Renal colic $34.9 \%$ of ESWL group versus $20.4 \%$ of URS one. Post-operative fever $4.8 \%$ in ESWL group versus $1.9 \%$ for URS one. Stone cone catheters were used in URS group to prevent stone migration into the kidney due to close proximity of the stone to PUJ .Relatively lower post-operative pain for ESWL and URS groups due to fine fragments. Stone migration rate was higher in our study because we didn`t use stone cone catheters.

In our study, 16 out of 19 cases $(84.2 \%)$ of the ESWL group were stone free versus $17(89.5 \%)$ of 19 cases of the URS group. Of the nineteen cases treated by ESWL, 4 cases became stone free after the 1st ESWL session $(21 \%)$. This means that the stone-free rate after the 1st session of URS was greatly more than that after the 1 st session of ESWL. 5 cases $(26.3 \%)$ were stone-free after the 2nd SWL session. 7cases (36.8\%) were stonefree after three sessions of ESWL. While, the stone free rate (SFR) was $100 \%$ in the stones $\leq 10 \mathrm{~mm}$ of ESWL group versus $89 \%$ in URS group. Regarding the Stones $>10 \mathrm{~mm}$ but $\leq 15 \mathrm{~mm}$, the SFR was $72.7 \%$ and $90 \%$ in ESWL and URS groups respectively with no statistically significant difference between both modalities despite the numerical difference in favor of ESWL for stones $\leq 10 \mathrm{~mm}$ but the reverse for stones $>10$ mm. In Yencilek et al. ${ }^{(17)}, 77$ out of 83 patients (92\%) in ESWL group were stone-free after three sessions and 41 patients $(75 \%)$ were stone-free in URS group. Stone-free rate (SFR) was $67.4 \%$ after the 1st session of ESWL and $81.9 \%$ were stone-free after the 2 nd one.In Cui et $\boldsymbol{a l} .{ }^{\left({ }^{(11)} \text {, }\right.}$ (92.5\%) of patients in ESWL group were stone free versus (97.5\%) of the URS group. SFR was $77.5 \%$ after the 1 st session of ESWL and $87.5 \%$ were stone free after the 2nd session and $92.5 \%$ after the 3rd session.In our study, the lower SFR was due to failure of ESWL in 3 cases. It was due to impacted stone in edematous ureteric wall in one case and Stein Strasse formation in the other 2 cases. These patients were eventually managed by ureteroscopy and became stone free.

Concerning the SFR of the ureteroscopy group in our study, 17 out of 19 cases $(89.5 \%)$ were stone-free after a single procedure. The failed 2 cases were due to stone migration into the kidney in one case and the other case was terminated due to tight ureter with subsequent failure of ureteroscope access to the stone and eventually extravasation after multiple attempts of ureteroscope 
access. A JJ stent was inserted in these two cases and managed by ESWL.

In Yencilek et $\boldsymbol{a l}$. $^{(17)}, 41$ out of 54 cases (75.9\%) were stone-free after a single procedure in semirigid URS group. Of the 13 failures $(24.1 \%)$ in the URS group, the most frequent cause was stone migration into the kidney $(n=9,16.7 \%)$, followed by blurred vision due to evident hematuria $(n=2,3.7 \%)$, inability to reach the stone because of prominent angulation of the proximal ureter $(\mathrm{n}=1,1.9 \%)$ and ureteric avulsion $(\mathrm{n}=1,1.9 \%)$.

$14(73.7 \%)$ cases of URS group had JJ stents because of stone migration $(n=1)$, balloon dilatation of the pin point ureteric orifice $(n=5)$, mucosal injury $(n=1)$ and residuals $(n=7)$. The rest of URS group $5(26.5 \%)$ had a ureteric catheter that was removed 24 hours postoperatively. No cases in ESWL group had preoperative JJ stents as both modalities were considered a primary modality of treatment.

In Yencilek et al. ${ }^{(17)}, 15$ out of 54 patients (27.8\%) in the URS group received JJ stents because of stone migration $(n=9)$, gross hematuria $(n=2)$, balloon dilatation of the ureteric orifice $(n=2)$, or ureteric stricture $(n=2)$.

\section{CONCLUSION}

ESWL and Ho-YAG laser lithotripsy are comparable in managing the proximal ureteric stone in term of safety and efficacy. URS has the advantage of the higher SFR from the first session without need of multiple hospital visits and prolonged radiation exposure time. ESWL has the advantage of no need of anesthesia and no hospital stay as it was done as outpatient and this should be considered when counselling the patient with proximal ureteric stone.

\section{REFERENCES}

1. Pearle MS, Calhoun EA, Curhan GC et al. (2005): Urologic diseases in America project: urolithiasis. The Journal of urology, 173(3):848-57.

2. Lee SW, Woo SH, Yoo DS, Park J (2014): Effect of tamsulosin on stone expulsion in proximal ureteral calculi: an open label randomized controlled trial. International journal of clinical practice, 68(2):216-21.

3. Ichiyanagi O, Nagaoka A, Izumi T, Kawamura Y, Kato T (2015): Age-related delay in urinary stone clearance in elderly patients with solitary proximal ureteral calculi treated by extracorporeal shock wave lithotripsy. Urolithiasis, 43(5):419-26.

4. Yang C, Li S, Cui Y (2017): Comparison of YAG Laser Lithotripsy and Extracorporeal Shock Wave Lithotripsy in Treatment of Ureteral Calculi: A Meta-Analysis. Urol Int., 98:373-381

5. Park J, Kim HW, Hong S, Yang HJ, Chung H (2015): Comparison of treatment outcomes according to output voltage during shockwave lithotripsy for ureteral calculi: a prospective randomized multicenter study. World journal of urology, 33(5):609-15.

6. Yencilek F, Sarica K, Erturhan S, Yagci F, Erbagci A (2010): Treatment of ureteral calculi with semirigid ureteroscopy: where should we stop? Urol Int., 84:260-4.
7. Marchant F, Storme O, Osorio F, Benavides J, Palma C et al. (2009): Prospective trial comparing shock wave lithotripsy and ureteroscopy for management of distal ureteral calculi. ActasUrol Esp., 33: 869-872.

8. Beetz R, Bökenkamp A, Brandis M, Hoyer P, John U, Kemper M et al. (2001): Diagnosis of congenital dilatation of the urinary tract. Urologe A., 40(6):495-507.

9. Bader MJ, Eisner B, Porpiglia F et al. (2012): Contemporary manage- ment of ureteral stones. Eur Urol., 61: 746-772.

10. Chaussy C, Eisenberger F, Forssmann B (2007): Extracorporeal shock wave lithotripsy (ESWL®): a chronology. J Endourol., 21: 1249-1253.

11. Cui Y, Cao W, Shen H, Xie J, Adams TS, Zhang Y, Shao Q (2014): Comparison of ESWL and ureteroscopic holmium laser lithotripsy in management of ureteral stones. PloS one, 9(2): e87634.

12. Lieske JC, De La Vega LP, Slezak JM, Bergstralh EJ, Leibson CL, Ho KL, Gettman MT (2006): Renal stone epidemiology in Rochester, Minnesota: an update. Kidney international, 69(4):760-4.

13. Sofia NH,Walter TM (2016): Prevalence and risk factors of kidney stone. Global Journal For Research Analysis, 5(3):183-7.

14. Wong YV, Cook P, Somani BK(2015): The association of metabolic syndrome and urolithiasis. Int $\mathbf{J}$ Endocrinol. , 2015:570674.

15. Lopes Neto AC, Korkes F, Silva JL, Amarante RD, Mattos MH, Tobias-Machado M, Pompeo AC (2012): Prospective randomized study of treatment of large proximal ureteral stones: extracorporeal shock wave lithotripsy versus ureterolithotripsy versus laparoscopy. The Journal of urology, 187(1):164-8.

16. Pareek G, Armenakas NA, Fracchia JA (2003): Hounsfield units on computerized tomography predict stone-free rates after extracorporeal shock wave lithotripsy. The Journal of urology, 169(5):1679-81.

17. Yencilek F, Sarica K, Gürpinar T, Göktas C, Cangüven Ö, Albayrak S (2009): A comparison of shock wave lithotripsy, semirigid and flexible ureteroscopy in the management of proximal ureteral calculi/Proksimalüretertaslarinintedavisindesokdalgatedavisi, semirijid ve fleksiblüreteroskopininkarsilastirilmasi. Turkish Journal of Urology, 35(2):101.

18. Pricop C, Maier A, Negru D et al. (2014): Extracorporeal shock waves lithotripsy versus retrograde ureteroscopy: is radiation exposure a criterion when we choose which modern treatment to apply for ureteric stones? Bosn J Basic Med Sci., 14(4):254- 258.

19. Vural A, Oguz V,Oktenl C, Yenicesu M, Caglar $\mathrm{K}$ et al. (1998): Detection of Source of Haematuria after Extracorporeal Shock Wave Lithotripsy (ESWL) by Automated Measurement of Urinary Red Cell Volume. IntUrolNephrol., 30: 31-37.

20. Joshi HB, Newns N, Stainthorpe A, MacDonagh RP, Keeley FX et al. (2003): Ureteral stent symptom questionnaire: development and validation of a multidimensional quality of life measure. J Urol., 169: 10601064.

21. Lamb AD, Vowler SL, Johnston R, Dunn N, Wiseman OJ (2011): Meta-analysis showing the beneficial effect of $\alpha$ blockers on ureteric stent discomfort. BJU Int., 108: 18941902.

22. Wang CJ, Huang SW, Chang CH (2009): Effects of tamsulosin on lower urinary tract symptoms due to double-J stent: a prospective study. Urol Int., 83: 66-69. 